\title{
Human $\mathrm{P}^{2} \mathrm{Y}_{6}$ Receptor: Molecular Modeling Leads to the Rational Design of a Novel Agonist Based on a Unique Conformational Preference
}

\author{
Stefano Costanzi ${ }^{\mathrm{a}}$, Bhalchandra V. Joshi ${ }^{\mathrm{b}}$, Savitri Maddileti ${ }^{\mathrm{C}}$, Liaman Mamedova ${ }^{\mathrm{b}}$, Maria J. \\ Gonzalez-Moad $^{\mathrm{d}}$, Victor E. Marquez ${ }^{\mathrm{d}}$, T. Kendall Harden ${ }^{\mathrm{C}}$, and Kenneth A. Jacobson ${ }^{\mathrm{b}}$ \\ aComputational Chemistry Core Laboratory, NIDDK, National Institutes of Health, DHHS, Bethesda, MD \\ 20892, USA.
}

bMolecular Recognition Section, NIDDK, National Institutes of Health, DHHS, Bethesda, MD 20892, USA.

cDepartment of Pharmacology, University of North Carolina, School of Medicine, Chapel Hill, NC 27599, USA.

dLaboratory of Medicinal Chemistry, NCI, National Institutes of Health, DHHS, Frederick, MD 21702, USA

\begin{abstract}
Combining molecular dynamics (MD) in a hydrated phospholipids (DOPC) bilayer, Monte Carlo search, and synthesis of locked nucleotide analogues we discovered that the Southern conformation of the ribose is preferred for ligand recognition by the $\mathrm{P}_{2} \mathrm{Y}_{6}$ receptor. 2'-Deoxy-(S)methanocarbaUDP was found to be a full agonist of the receptor and displayed a 10-fold higher potency than the corresponding flexible 2 '-deoxyUDP. MD results also suggested a conformational change of the second extracellular loop consequent to agonist binding.
\end{abstract}

P2Y receptors are a family of class A G protein-coupled receptors (GPCRs), variously activated by extracellular purine and pyrimidine nucleotides. ${ }^{1,2}$ The family is composed of two distinct subgroups, which differ in overall sequence similarity, mechanism of ligand recognition, and coupling to second messengers. The $\mathrm{P}_{2} \mathrm{Y}_{1}$-like subgroup encompasses the $\mathrm{P}_{2} \mathrm{Y}_{1}, \mathrm{P}_{2} \mathrm{Y}_{2}$, $\mathrm{P}_{2} \mathrm{Y}_{4}, \mathrm{P}_{2} \mathrm{Y}_{6}$, and $\mathrm{P} 2 \mathrm{Y}_{11}$ receptors, which couple mainly to the stimulation of phospholipase $\mathrm{C}$ (PLC) via $\mathrm{G}_{\mathrm{q}}$. On the other hand, the $\mathrm{P}_{2} \mathrm{Y}_{12}$-like subgroup encompasses the P2 $\mathrm{Y}_{12}, \mathrm{P}_{2} \mathrm{Y}_{13}$, and $\mathrm{P}_{2} \mathrm{Y}_{14}$ receptors, which couple mainly to the inhibition of adenylyl cyclase (AC) via $\mathrm{G}_{\mathrm{i}}$. The $\mathrm{P}_{2} \mathrm{Y}_{6}$ receptor is the only $\mathrm{P} 2 \mathrm{Y}$ receptor whose natural agonist is uridine-5'-diphosphate (UDP, 1). It is the least studied subtype of the $\mathrm{P}_{2} \mathrm{Y}_{1}$-like subgroup, due to the lack of potent and selective ligands. It has recently been shown that the activation of the $\mathrm{P}_{2} \mathrm{Y}_{6}$ receptor induces $\mathrm{Ca}^{2+}$ and $\mathrm{Cl}^{-}$secretion in mouse trachea. Hence, $\mathrm{P}_{2} \mathrm{Y}_{6}$ agonists may be useful to stimulate electrolyte transport in the airways of cystic fibrosis patients. ${ }^{3}$

It is known that the five-membered ring of the ribose moiety of nucleosides and nucleotides can adopt a range of conformations, which can be exhaustively described by two parameters indicative of puckering: $\mathrm{P}$ (phase angle of pseudorotation, schematically represented as a pseudorotational cycle) and $\theta$ (puckering amplitude). ${ }^{4,5}$ Using conformationally-locked nucleotide analogues, we deduced a preference for the Northern $(\mathrm{N})$ hemisphere of the pseudorotational cycle (2'-exo, 3'-endo) for the $\mathrm{P}_{2} \mathrm{Y}_{1}, \mathrm{P}_{2} \mathrm{Y}_{2}, \mathrm{P}_{2} \mathrm{Y}_{4}$, and $\mathrm{P}_{2} \mathrm{Y}_{11}$ receptors. 4,6 , 7,8 However, the UDP analogue 2 locked in the $(\mathrm{N})$ conformation by a $(\mathrm{N})$-methanocarba 
system was found completely inactive (Figure 1) ${ }^{7}$ Hence, prior to this work, the $\mathrm{P} 2 \mathrm{Y}_{6}$ receptor has been the most elusive subtype of the $\mathrm{P}_{2} \mathrm{Y}_{1}$-like receptors and the conformation of the ribose moiety of UDP required for the recognition of the ligand was not established.

Here we report the discovery of the biologically-active conformation of the sugar moiety of UDP, which we accomplished by means of an interdisciplinary approach combining advanced molecular modeling techniques with the synthesis of conformationally locked nucleotide analogs. This finding represents a breakthrough toward the understanding of the biology of the $\mathrm{P}_{2} \mathrm{Y}_{6}$ receptor, as it may be the key to the design of the long needed pharmacological tools.

To obtain a refined model of the $\mathrm{P}_{2} \mathrm{Y}_{6}$ receptor that could be exploited to identify the conformation of the ribose moiety required for the molecular recognition of UDP, we submitted our rhodopsin-based homology model of the receptor ${ }^{1}$ to $10 \mathrm{~ns}$ of molecular dynamics (MD) in a fully hydrated phospholipid (dioleoylphosphatidylcholine, DOPC) bilayer, which was constructed around the receptor according to a modification of the stepwise procedure developed by Woolf and Roux. ${ }^{9}$ The simulated system was composed of the $\mathrm{P}_{2} \mathrm{Y}_{6}$ receptor, 100 DOPC molecules evenly distributed between the extracellular and the intracellular sides, 6030 water molecules, and $19 \mathrm{Cl}^{-}$ions, which were added in order to neutralize the total charge of the system. The simulation was conducted with the program CHARMM ${ }^{10}$ under constant pressure and temperature conditions $(\mathrm{P}=1 \mathrm{~atm} ; \mathrm{T}=310 \mathrm{~K})$, with periodic hexagonal boundary conditions applied in all directions, to simulate a multilayer of infinite membranes.

To date, bovine rhodopsin is the only GPCR for which an experimental structure has been elucidated, and therefore is the only suitable template for the construction of homology models of the other members of the superfamily. Homology modeling has proven to be a very powerful technique, even when the template and the protein to be modeled are only distantly related.

${ }^{11}$ However, although a common general structure is likely to be shared by all GPCRs, specific differences do exist between rhodopsin and the other receptors. In particular, many GPCRs, including the P2Y receptors, show a different distribution of Pro residues within the 7 transmembrane (TM) domains when compared to rhodopsin, suggesting the likelihood of conformational differences. ${ }^{1}$ Moreover, the intracellular and extracellular regions of the GPCRs show a high variability in the amino acid sequence, which suggests a very limited structural similarity to rhodopsin. An MD simulation of a membrane protein in a hydrated lipid bilayer permits an unconstrained relaxation of the protein model within the context of its natural environment, allowing the backbone and the side chains to search for a stable conformation.

In Figure 2a we report a superimposition of the $\mathrm{P}_{2} \mathrm{Y}_{6}$ homology model and the typical structure occurring in the timeframe from 9.9 to $10 \mathrm{~ns}$ of the MD simulation. In order to facilitate the comparison among receptors, throughout this paper we use the GPCR residue indexing system, as explained in the supporting information. Although the overall structure of the helical bundle was conserved throughout the MD simulation, a root mean square deviation (RMSD) of 2.70 $\AA$ was found between the backbone of the 7 TMs of the initial and the final structures. In particular, the $\mathrm{P}_{2} \mathrm{Y}_{6}$ receptor contains four Pro residues, not conserved in rhodopsin, at positions 1.36, 1.37, 2.58, and 7.40. These Pro residues caused the formation of kinks in the upper segments of TM1, TM2, and TM7 during the MD simulation. The amphipathic helix 8 (H8), located at the cytoplasmic end of TM7, at the interface between the lipid bilayer and the cytosolic water, remained stable throughout the trajectory (Figure 2a). Among the extracellular regions, the second extracellular loop (EL2) has been recognized as particularly important for the ligand recognition and for the activation of various GPCRs, including the P2Y receptors. $12,13,14$ In rhodopsin, and hence in our initial homology model of the $\mathrm{P} 2 \mathrm{Y}_{6}$ receptor, EL2 forms a $\beta$-hairpin parallel to the plane of the membrane, which occludes the entry to the cavity within the helical bundle. In our MD simulation of the $\mathrm{P}_{2} \mathrm{Y}_{6}$ receptor, EL2 moved toward TM3 
and further up into the extracellular space, making the putative nucleotide binding site accessible to an approaching ligand.

The typical structure of the system occurring during the timeframe from 9.9 to $10 \mathrm{~ns}$ of the MD was used for the ligand docking experiments. UDP was positioned into the putative binding pocket in line with our previously published binding mode of nucleotides at the $\mathrm{P}_{2} \mathrm{Y}_{1}$-like receptors. ${ }^{1,4}$ According to this experimentally supported binding mode, the sugar moiety is located between TM3 and TM7, the base points toward TM1 and TM2, while the diphosphate moiety points in the direction of TM6.

A conformational analysis of the ligand inside the binding pocket, with particular attention to the sugar puckering, was conducted by means of the Monte Carlo Multiple Minimum (MCMM) conformational sampling as implemented in MacroModel (Schrödinger, LLC). In order to keep the bias on the ribose puckering as low as possible, the search was seeded with one UDP molecule in the $(\mathrm{N})$ and one in the Southern ( $(\mathrm{S}), 2^{\prime}$-endo, 3'-exo) conformation, minimized within the binding pocket. All the torsional angles of the ligand and the side chains of the residues within $5 \AA$ from the ligand were subjected to the Monte Carlo search. At the same time, the ligand was subjected to Monte Carlo rotations and translations.

The search produced ten receptor-ligand complexes compatible with our previously published $^{1,4}$ binding mode. The ten complexes fell into two distinct clusters, which identified two overlapping binding modes of UDP within the exofacial side of the cavity delineated by TM1, TM2, TM3, TM6, and TM7 (Figure 2b). The more external pocket (Figure 2c) could be a meta-binding site to which the ligand binds in its path to the principal binding site. Similar meta-binding sites have been previously hypothesized for the $\mathrm{P} 2 \mathrm{Y}_{1}$ receptor. ${ }^{15}$ The metabinding site cluster was composed of three receptor-ligand complexes, two with UDP in the (S) conformation and one with UDP in the $(\mathrm{N})$ conformation. The more deeply buried binding site cluster consisted of seven receptor-ligand complexes, all with UDP in the (S) conformation (Figure 2d). Thus, our conformational search indicated a clear preference of $\mathrm{P}_{2} \mathrm{Y}_{6}$ for the (S) conformation of the ribose moiety of UDP. Although UDP could bind to the meta-binding site in the $(\mathrm{N})$ conformation, the $(\mathrm{S})$ conformation seemed to be exclusively required for binding to the principal binding site.

In all the docking poses (Figure $2 b-d$ ), the phosphate moiety of UDP bound to the same positively charged sub-pocket formed by three cationic amino acids from TM3, TM6, and TM7, namely R103(3.29), K259(6.55), and R287(7.39). These residues, which are conserved in all the subtypes of the $\mathrm{P} 2 \mathrm{Y}_{1}$-like subgroup of the $\mathrm{P} 2 \mathrm{Y}$ receptors, were found essential for the activation of the $\mathrm{P} 2 \mathrm{Y}_{1}$ receptor by nucleotides in site-directed mutagenesis experiments. 16 Our previous molecular modeling studies suggested their involvement in the coordination of the phosphate moieties in all the $\mathrm{P}_{2} \mathrm{Y}_{1}$-like receptors. ${ }^{1}$ The fact that in the meta-binding site the diphosphate moiety of UDP was already bound to the aforementioned positively-charged pocket, suggests that the electrostatic attraction between this pocket and the negatively charged diphosphate could be the driving force of the ligand binding process.

In the principal binding site the conserved S291(7.43) was involved in the coordination of the 2-O of the pyrimidine moiety of UDP (Figure 2). S7.43 was also found essential for the activation of $\mathrm{P}_{2} \mathrm{Y}_{1}$ by nucleotides, ${ }^{16}$ and was suggested to be involved in the coordination of the nucleobase on the basis of molecular modeling results. ${ }^{1}$ Conversely, in the meta-binding site S291(7.43) was hydrogen bonded to Y33(1.39). Molecular modeling results had previously suggested the importance of the H-bond between the conserved Y1.39 and S7.43 in the stabilization of the ground state of the P2Y receptors. ${ }^{1}$ The loss of this H-bond consequent to shifting of UDP from the meta- to the principal binding site, could play a role in the activation 
of the receptor. Mutagenesis studies aimed at further investigating this working hypothesis are currently ongoing in our laboratories.

In order to refine the receptor-ligand interactions and to study the stability of the (S) conformation of UDP within the receptor binding pocket, a $\mathrm{P} 2 \mathrm{Y}_{6}$-UDP complex representative of the principal binding site was submitted to $5 \mathrm{~ns}$ of MD in the DOPC bilayer environment. The typical structure occurring in the timeframe from 14.9 to $15 \mathrm{~ns}$ of the MD simulation is represented in Figure 2e. The interactions among the diphosphate moiety of UDP and the three cationic residues from TM3, TM6, and TM7 remained stable throughout the $5 \mathrm{~ns}$ of MD. Y283 (7.35) also engaged a stable $\mathrm{H}$-bond with the diphosphate. Consistently, we previously found that Ala and Phe mutations of the corresponding residue in the $\mathrm{P} 2 \mathrm{Y}_{1}$ receptor led to 10 -fold reduced affinity for the agonist 2-MeSADP. ${ }^{1}$ The role of $\mathrm{Y} 7.35$ in the ligand binding could not be established in docking experiments conducted prior to MD. The 3'-OH group of UDP established stable H-bonds, mediated by a water molecule, with K259(6.55) and, intramolecularly, with the 5'-O. The interaction between S291(7.43) and the 2-O of UDP remained stable throughout the simulation, and Y33(1.39) established a stable $\mathrm{H}$-bond with the 1-NH of UDP. The uracil ring was stabilized by hydrophobic interactions with the conserved residues F106(3.32), L29(1.35), and I83(2.61).

An electrostatic interaction between R103(3.29) and the conserved D179(EL2) was stable throughout the $10 \mathrm{~ns}$ of the MD of the unoccupied $\mathrm{P} 2 \mathrm{Y}_{6}$ and was lost in the MD of the $\mathrm{P} 2 \mathrm{Y}_{6^{-}}$ UDP complex. In fact, R103(3.29) engaged in electrostatic interaction with the diphosphate moiety of UDP, while D179(EL2) was repelled toward the extracellular space by the negative charge of the ligand (Figure 2f). The R103(3.29)-D179(EL2) interaction, which seems fundamental in the stabilization of the unoccupied $\mathrm{P}_{2} \mathrm{Y}_{6}$ receptor, could not be detected prior to the MD simulation. The presence of the ligand in the $\mathrm{P}_{2} \mathrm{Y}_{6}$ binding pocket caused the disruption of this interaction and a consequent substantial conformational change of EL2, whose backbone showed an RMSD of $3.81 \AA$ between the typical structures of the unoccupied and occupied receptors. A movement of EL2 is associated with the activation of other GPCRs. 13,14 Previous studies suggested that the corresponding R128(3.29) and D204(EL2) of the $\mathrm{P}_{2} \mathrm{Y}_{1}$ receptor are involved in the process of ligand recognition and/or receptor activation, since in both cases a mutation to Ala highly impaired the ability of the agonist 2-MeSATP to stimulate the receptor. ${ }^{12,16}$ Our MD simulation suggests a similar role for the corresponding residues of the $\mathrm{P}_{2} \mathrm{Y}_{6}$ receptor; however, for $\mathrm{P}_{2} \mathrm{Y}_{6}$ as well as the other subtypes of the $\mathrm{P} 2 \mathrm{Y}$ receptors, this hypothesis remains to be tested using mutagenesis experiments. Besides EL2, the backbone of the $\mathrm{P} 2 \mathrm{Y}_{6}$ receptor did not show significant changes after the $5 \mathrm{~ns}$ of $\mathrm{MD}$ in complex with the ligand. The average RMSD between the backbone of the typical structures of the unoccupied and the occupied receptors was $1.14 \AA$ for the TMs and $2.29 \AA$ for the loops, excluding EL2.

The ribose moiety of UDP maintained stable torsional angles throughout the simulation, showing, in the final typical structure, a $\mathrm{P}$ of $180^{\circ}$ and a $\theta$ of $36^{\circ}$, indicative a pure (S) conformation. We have reported elsewhere the formulae to derive $\mathrm{P}$ and $\theta$ from the five torsional angles of a five-membered ring. ${ }^{4}$ During the whole time of the simulation, the (S) conformation of the ribose ring ensured the optimal fitting of the sugar moiety of UDP in the $\mathrm{P}_{2} \mathrm{Y}_{6}$ binding pocket. Furthermore, it conferred to the phosphate and the nucleobase moieties the most favorable orientation for the establishment of interactions with the residues from TM1, TM3, TM6, and TM7 (Figure 2e).

On the basis of the molecular modeling results, we devised the synthesis of a carbocyclic analogue of UDP locked in the (S) conformation by a (S)-methanocarba modification of the ribose ring. The methanocarba system, introduced by Marquez and coworkers, consists of a cyclopentane ring fused with a cyclopropane ring and can be used to constrain a pseudosugar 
ring in the $(\mathrm{N})$ or the $(\mathrm{S})$ conformations, depending on the position of the fusion. ${ }^{17}$ The starting nucleoside necessary for the synthesis of the enantiomerically pure (S)-2'-deoxy-

methanocarbaUDP was readily available in our laboratories, since it was earlier synthesized and tested for its antiviral activity by Marquez and coworkers. ${ }^{18}$ Furthermore, we inferred from the model that the 2'-OH group, although important in the stabilization of the ligand through an intramolecular H-bond with the 2-O, was not involved in crucial interactions with the receptor. Therefore, we evaluated the potency and the efficacy of $2^{\prime}$-deoxyUDP $(3)$ in activation of PLC in 1321N1 astrocytoma cells stably transfected with the human P2Y 6 receptor, and discovered that, although less potent than UDP (1), it maintained full agonistic activity at the $\mathrm{P}_{2} \mathrm{Y}_{6}$ receptor (Table 1, Figure 1). Hence, in order to verify the modeling predictions and to accelerate the lead discovery process we decided to synthesize the (S)-2'deoxy-methanocarbaUDP (10) rather than the (S)-methanocarbaUDP. The synthesis began with the (S)-2'-deoxy-methanocarba uridine (4), which was prepared according to the procedure previously reported by Marquez et al. ${ }^{18}$ The (S)-2'-deoxy-methanocarba uridine (4) was treated sequentially with $t$-butyldiphenylsilyl chloride and dihydropyran to give the protected uridine derivative 6 . Selective deprotection of the 5'-silyl group was achieved by the reaction of 6 with $1 \mathrm{M}$ tetrabutylammonium fluoride solution in tetrahydrofuran to afford $\mathbf{7}$ in $66 \%$ yield. Nucleoside 7 was sequentially phosphorylated by first reacting with di-t-butyl $N, N$-diethylphosphoramidite and tetrazole followed by treatment with $m$-chloroperbenzoic acid to afford the di-t-butyl phosphate derivative 8 in $45 \%$ yield. Both di-t-butyl and the THP groups in $\mathbf{8}$ were deprotected simultaneously by using $10 \%$ trifluoroacetic acid solution to afford the monophosphate 9 in $60 \%$ yield. The requisite diphosphorylation of 9 was achieved by first reacting it with the 1,1'-carbonyldiimidazole, and subsequently reacting the resulting phosphoimidazolate in situ with phosphoric acid tributylammonium salt to afford the target of (S)-2'-deoxy-methanocarba 10 in $18 \%$ yield.

In agreement with the prediction by molecular modeling, not only was $\mathbf{1 0}$ found to be a full agonist of the $\mathrm{P}_{2} \mathrm{Y}_{6}$ receptor, but it displayed an $\mathrm{EC}_{50}$ of $0.23 \mu \mathrm{M}$ and proved to be 10-fold more potent than the corresponding 2-deoxyUDP 3 (Table 1, Figure 1).

In conclusion, compound $\mathbf{1 0}$ represents a successful case of structure-based drug design, and is the first example of a nucleotide locked in the (S) conformation found to activate any P2Y subtype. The discovery of the activity of this novel locked nucleotide provides the first lead for the development of potent and selective $\mathrm{P}_{2} \mathrm{Y}_{6}$ ligands, which are essential to further characterize this receptor. The synthesis of the (S)-methanocarbaUDP, which is expected to be more potent than its $2^{\prime}$-deoxy analogue is currently in progress. Through the lead optimization process, we aim to find a good candidate for the development of a radioligand for the $\mathrm{P}_{2} \mathrm{Y}_{6}$ receptor, which would prove fundamental to distinguish the processes of binding and ligand recognition, therefore allowing further testing of the molecular modeling hypothesis and consequently a more profound understanding of molecular determinants of the ligand recognition, of the mechanisms involved in the receptor activation, and of the structure activity relationships.

\section{Supplementary Material}

Refer to Web version on PubMed Central for supplementary material.

\section{Acknowledgements}

The authors thank Dr. Anny-Odile Colson for helpful the discussions on molecular modeling. This research was supported in part by the Intramural Research Program of the NIH, NIDDK. 


\section{References}

1. Costanzi S, Mamedova L, Gao Z-G, Jacobson KA. Architecture of P2Y nucleotide receptors: structural comparison based on sequence analysis, mutagenesis, and homology modeling. J. Med. Chem 2004;47:5393-5404. [PubMed: 15481977]

2. Boeynaems JM, Communi D, Gonzales NS, Robaye B. Overview of the P2 receptors. Semin, Tromb. Hemost 2005;31:139-149.

3. Schreiber R, Kunzelmann K. Purinergic $\mathrm{P}_{2} \mathrm{Y}_{6}$ receptors induce $\mathrm{Ca}^{2+}$ and $\mathrm{CFTR}$ dependent $\mathrm{Cl}^{-}$ secretion in mouse trachea. Cell. Physiol. Biochem 2005;16:99-108. [PubMed: 16121038]

4. Ohno M, Costanzi S, Kim HS, Kempeneers V, Vastmans K, Herdewijn P, Maddileti S, Gao Z-G, Harden TK, Jacobson KA. Nucleotide analogues containing 2-oxa-bicyclo[2.2.1]heptane and L- $\alpha$ threofuranosyl ring systems: interactions with P2Y receptors. Bioorg. Med. Chem 2004;12:56195630. [PubMed: 15465340]

5. Saenger, W. Principle in nucleic acid structure. New York, Berlin, Heidelberg: Springer-Verlag; 1984. p. 9-28.

6. Jacobson KA, Ji X-d, Li AH, Melman N, Siddiqui MA, Shin KJ, Marquez VE, Ravi RG. Methanocarba analogues of purine nucleosides as potent and selective adenosine receptor agonists. J. Med. Chem 2000;43:2196-2203. [PubMed: 10841798]

7. Kim HS, Ravi RG, Marquez VE, Maddileti S, Wihlborg A-K, Erlinge D, Malmsjö M, Harden TK, Boyer JL, Jacobson KA. Methanocarba modification of uracil and adenine nucleotides: high potency of Northern ring conformation at $\mathrm{P}_{2} \mathrm{Y}_{1}, \mathrm{P}_{2} \mathrm{Y}_{2}, \mathrm{P}_{2} \mathrm{Y}_{4}$, and $\mathrm{P} 2 \mathrm{Y}_{11}$ but not $\mathrm{P} 2 \mathrm{Y}_{6}$ receptors. J. Med. Chem 2002;45:208-218. [PubMed: 11754592]

8. Boyer JL, Adams M, Ravi RG, Jacobson KA, Harden TK. Br. J. Pharmacol 2002;135:2004-2010. [PubMed: 11959804]

9. Woolf TB, Roux B. Structure, energetics, and dynamics of lipid-protein interactions: A molecular dynamics study of the gramicidin A channel in a DMPC bilayer. Proteins 1996;24:92-114. [PubMed: 8628736]

10. Brooks BR, Bruccoleri RE, Olafson BD, States DJ, Swaminathan S, Karplus M. CHARMM - a program for macromolecular energy, minimization, and dynamics calculations. J. Comput. Chem 1983;4:187-217.

11. Costanzi S, Vincenzetti S, Cristalli G, Vita A. Human cytidine deaminase: a three-dimensional homology model of a tetrameric metallo-enzyme inferred from the crystal structure of a distantly related dimeric homologue. J. Mol. Graph. Model. submitted.

12. Hoffmann C, Moro S, Nicholas RA, Harden TK, Jacobson KA. The role of amino acids in extracellular loops of the human $\mathrm{P}_{2} \mathrm{Y}_{1}$ receptor in surface expression and activation processes. J. Biol. Chem 1999;274:14639-14647. [PubMed: 10329657]

13. Klco JM, Wiegand CB, Narzinski K, Baranski TJ. Essential role for the second extracellular loop in C5a receptor activation. Nat. Struct. Mol. Biol 2005;12:320-326. [PubMed: 15768031]

14. Baneres JL, Mesnier D, Martin A, Joubert L, Dumuis A, Bockaert J. Molecular characterization of a purified 5-HT4 receptor: a structural basis for drug efficacy. J. Biol. Chem 2005;280:20253-20260. [PubMed: 15774473]

15. Moro S, Hoffmann C, Jacobson KA. Role of the extracellular loops of G protein-coupled receptors in ligand recognition: a molecular modeling study of the human $\mathrm{P} 2 \mathrm{Y}_{1}$ Receptor. Biochemistry 1999;38:3498-3507. [PubMed: 10090736]

16. Jiang Q, Guo D, Lee BX, van Rhee AM, Kim YC, Nicholas RA, Schachter JB, Harden TK, Jacobson KA. A mutational analysis of residues essential for ligand recognition at the human $\mathrm{P}_{2} \mathrm{Y}_{1}$ receptor. Mol. Pharmacol 1997;52:499-507. [PubMed: 9281613]

17. Marquez VE, Siddiqui MA, Ezzitouni A, Russ P, Wang J, Wagner RW, Matteucci MD. J. Med. Chem 1996;39:3739-3747. [PubMed: 8809162]

18. Ezzitouni A, Marquez VE. Conformationally locked carbocyclic nucleosides built on a bicyclo[3.1.0] hexane template with a fixed Southern conformation. Synthesis and antiviral activity. J. Chem. Soc. Perkin Trans. 1 1997:1073-1078. 


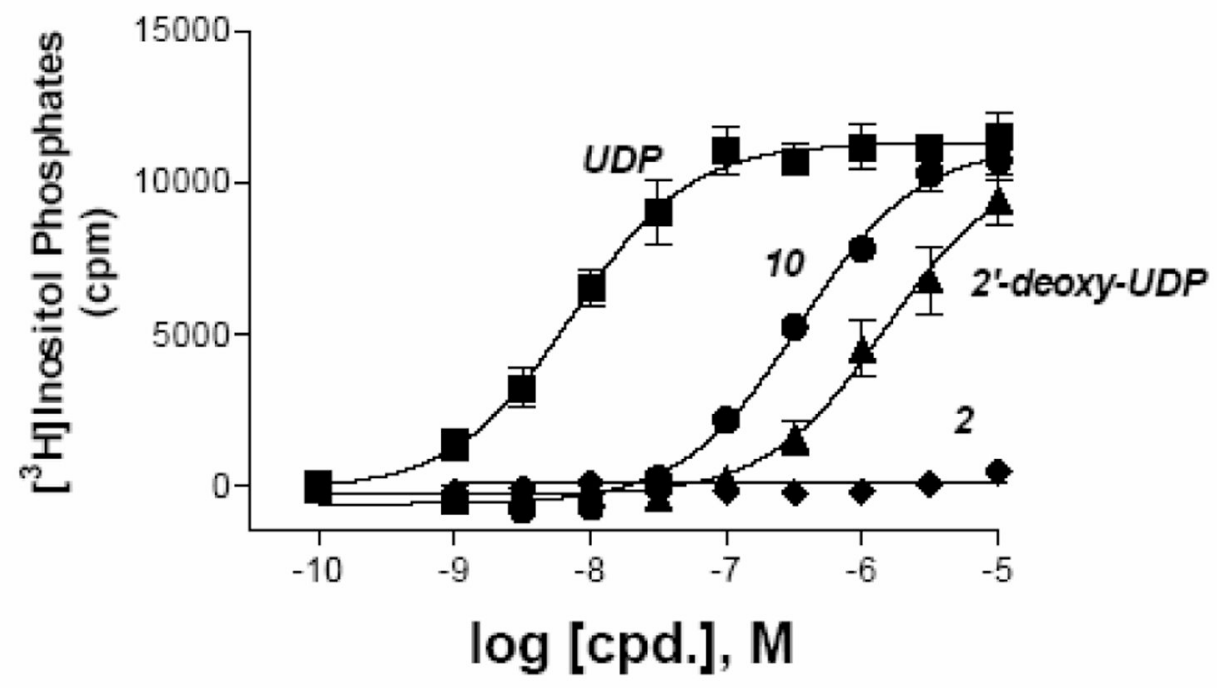

Figure 1.

Activation of the human $\mathrm{P}_{2} \mathrm{Y}_{6}$ receptors by uracil nucleotides. PLC activity was measured as described in the Supporting Materials in 1321N1 human astrocytoma cells stably expressing the receptor. The data are the means of triplicate determinations and are representative of results obtained in three separate experiments. 


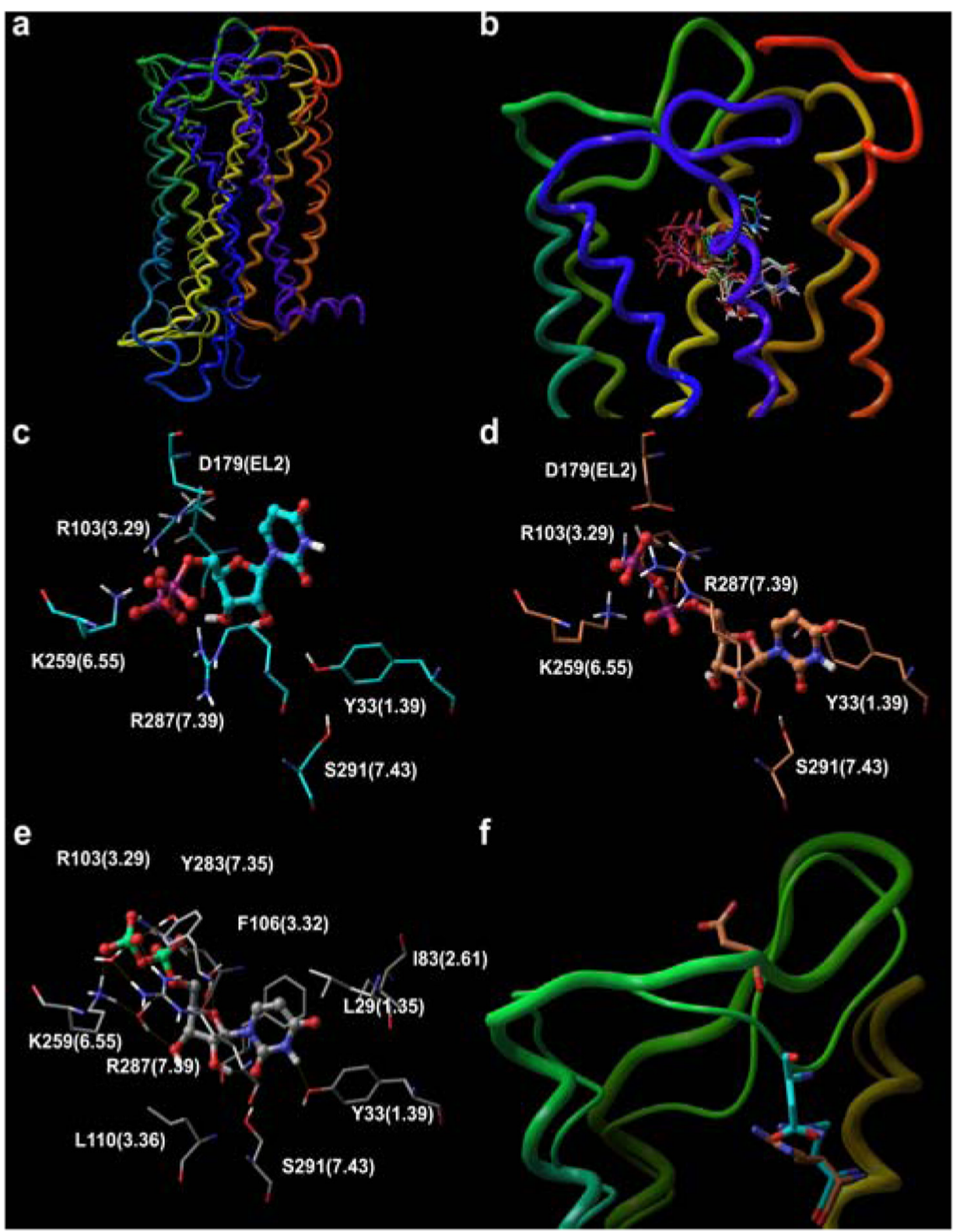

Figure 2.

a) The $\mathrm{P}_{2} \mathrm{Y}_{6}$ receptor before (thin tube) and after (thick tube) MD. b) Tube representation of $\mathrm{P}_{2} \mathrm{Y}_{6}$ with ten UDP molecules docked at the meta- and the principal binding sites. c \& d) Details of two complexes representative of the meta- (c) and the principal (d) binding sites. e) Typical structure of the $\mathrm{P}_{2} \mathrm{Y}_{6}$-UDP complex after 5 ns of MD. f) An electrostatic interaction between R103(3.29) and D179(EL2) is present in the unoccupied $\mathrm{P}_{2} \mathrm{Y}_{6}$ receptor (thin tube, cyan carbon atoms) and is lost upon MD of the receptor-ligand complex (thick tube, brown carbons). In the tube representations the receptor is colored according to residue positions, with a spectrum of colors that ranges from red (N-terminus) to purple (C-terminus): TM1 is in orange, TM2 in ochre, TM3 in yellow, TM4 in green, TM4 in cyan, TM5 in blue, TM7 in purple. 


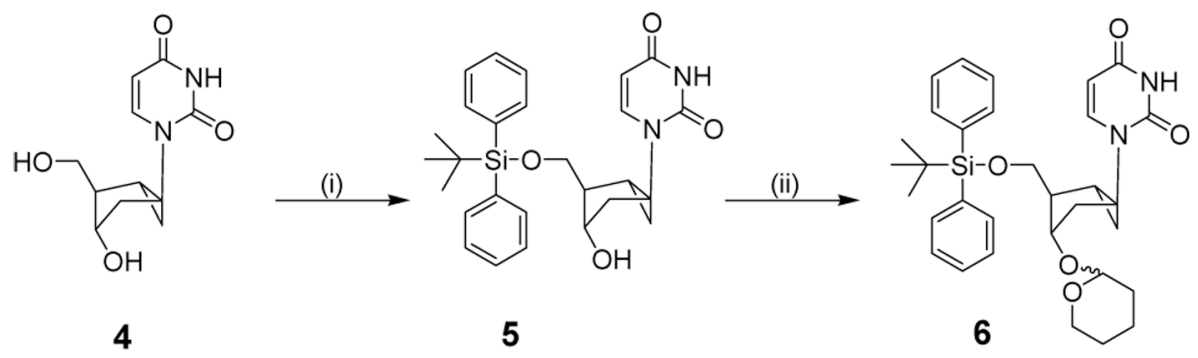

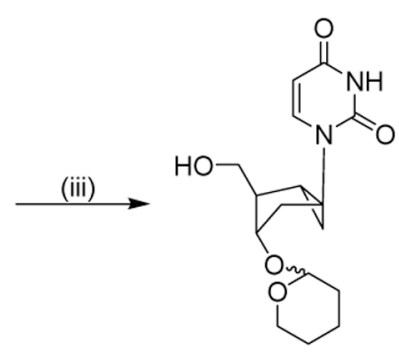

7

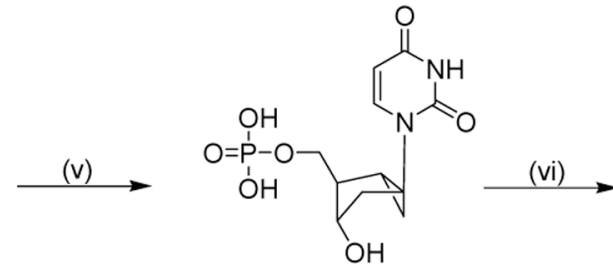

9<smiles>CC1CCCCCO1</smiles>

8<smiles>O=c1ccn(C2CC(O)C(COP(=O)(O)OP(=O)(O)O)C2)c(=O)[nH]1</smiles>

10

\section{Scheme 1.}

Reagents: (i) tert-butylchlorodiphenylsilane, imidazole, acetonitrile, r.t. (ii) dihydropyran, ptoluene sulphonic acid, dichloromethane, r.t. (iii) tetrabutylammoniun fluoride, (1M), THF, r.t. (iv) di-tert-butyl $\mathrm{N}, \mathrm{N}$-diethylphosphoramidite, tetrazole, $\mathrm{THF}$, r.t., $\mathrm{m}-\mathrm{CPBA},-78^{\circ} \mathrm{C}$, r.t. (v) $10 \%$ TFA (vi) a. 1,1'-carbonyldiimidazole, DMF, b. triethylamine, $\mathrm{MeOH}, \mathrm{H}_{2} \mathrm{O}$. c. tributylammonium phosphate, DMF, r.t. 

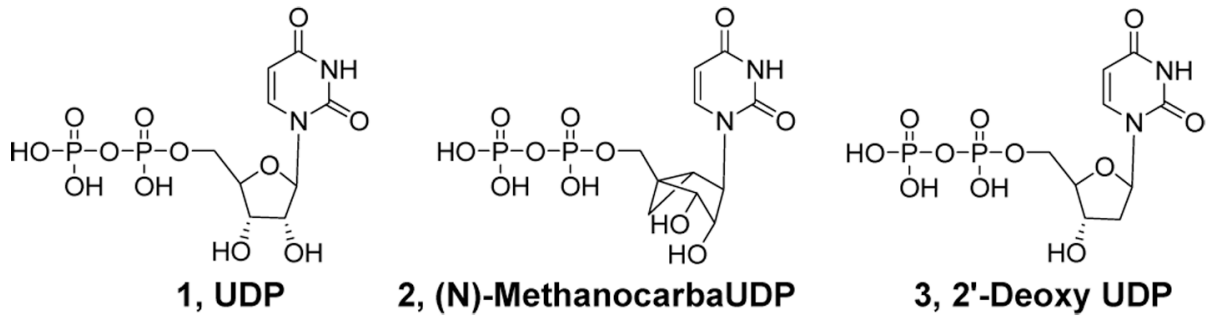

Chart 1.

J Med Chem. Author manuscript; available in PMC 2008 November 17. 
Table 1

$\mathrm{EC}_{50}$ values for stimulation of PLC in $1321 \mathrm{~N} 1$ astrocytoma cells stably transfected with the human $\mathrm{P}_{2} \mathrm{Y}_{6}$ receptor.

\begin{tabular}{ll}
\hline $\mathbf{C p d}$. & $\mathbf{P L C}_{\mathbf{E}} \mathbf{E \mathbf { S } _ { \mathbf { 5 } } ( \boldsymbol { \mu M } )}$ \\
\hline $\mathbf{1}$, UDP & $0.086 \pm 0.007$ \\
$\mathbf{2}$ & Inactive \\
$\mathbf{3}$, 2'deoxy-UDP $^{7}$ & $1.72 \pm 0.76$ \\
$\mathbf{1 0}$ & $0.23 \pm 0.05$ \\
\hline
\end{tabular}

